\title{
Desenvolvimento da técnica de deposição de filmes finos por gaiola catódica
}

\author{
Development the technique of deposition to thin films for cathodic cage
}

\author{
Cintia de L. R. Bottoni ${ }^{1}$, Danielly C. Gripa ${ }^{1}$, Leonardo C. Gontijo ${ }^{1}$
}

\begin{abstract}
Resumo
O presente trabalho tem por objetivo desenvolver a técnica de Deposição por plasma em descarga de gaiola catódica. Deposições de camadas de nitretos de ferro e de titânio foram realizadas sobre substrato de vidro em gaiola catódica, a partir de condições variadas de temperatura, tempo de deposição e razão da mistura $\mathrm{N}_{2}-\mathrm{H}_{2}$. Foram feitas análises de difratogramas de raios-X e ensaios de corrosão. As propriedades eletroquímicas dos filmes foram analisadas por de Espectroscopia de Impedância Eletroquímica (EIE) e curva de polarização, ambos em solução de $\mathrm{NaCl} 3,5 \%$ em peso. Com base nos espectros (EIE) foi possível observar que os filmes depositados possuem uma boa resistência à corrosão.
\end{abstract}

Palavras-chave: Deposição por plasma; Gaiola catódica; Filmes finos.

\begin{abstract}
This work has as main goal to develop the technique of deposition for plasma in discharge of cathodic cage. Deposition of layers the iron nitride and titanium nitride were realized on sample of glass in cathodic cage, under varying conditions of temperature, time of treatment and rate mixture of $\mathrm{H}_{2}-\mathrm{N}_{2}$. The characterion of samples was evidenced by X-ray difratogramas and tests of corrosion. The electrochemicals properties were investigated by electrochemical impedance spectroscopy (EIS) and potentidynamic polarization curve, both in $\mathrm{NaCl} 3.5 \% \mathrm{wt}$. solution. Based on spectrums (EIS) were possible to observe that thin films have a great result to resistance corrosion.
\end{abstract}

Keywords: Plasma deposition; Cathodic cage; Thin films. 


\section{Introdução}

Este trabalho visa o desenvolvimento da técnica de Deposição por plasma em descarga de gaiola catódica e posterior análise dos filmes formados de $\mathrm{Ti}_{x} \mathrm{~N}, \mathrm{Fe}_{x} \mathrm{~N}$. O equipamento de nitretação a plasma é usado também para a deposição de filmes em descarga de gaiola catódica $^{(1)}$. Para tanto são necessários compreenderemos quais os parâmetros que potencializam a nitretação e ou a deposição de filmes finos, além de buscarmos compreender sob quais condições podemos depositar filmes com baixa resistividade, alta transmitância e alta resistência a corrosão.

A gaiola catódica foi desenvolvida e patenteada pelo Laboratório de Processamento de Materiais por Plasma da Universidade Federal do Rio Grande do Norte (Labplasma) e consiste em uma chapa cilíndrica com furos e uma tampa circular também com furos similares ${ }^{(1,2)}$.

O plasma é formado na gaiola catódica, que funciona como cátodo (a parede da câmara é o ânodo) e não diretamente na superfície das amostras, que permanecem em potencial flutuante, posicionadas em uma superfície isolante $^{(3,5)}$. Desta maneira, observa-se a ocorrência de sputtering, processo no qual os átomos da gaiola são arrancados. Os átomos ejetados da gaiola, principalmente os dos furos da gaiola podem se combinar com o gás reativo da atmosfera do plasma e se depositar sobre a superfície da amostra, formando os filmes finos ${ }^{(4)}$.
Quando comparada às outras técnicas de deposição de filmes, a deposição por plasma em descarga de gaiola catódica é considerada uma técnica relativamente simples, pois necessita como aparato experimental apenas o nitretador convencional e a gaiola catódica, a qual é facilmente produzida ${ }^{(1)}$.

Os filmes de nitreto de ferro são bastante utilizados no meio científico acadêmico por permitir análises e aplicações diversificadas, enquanto que os filmes de nitreto de titânio vem sendo estudados por apresentarem combinação de propriedades como alta resistência à corrosão, boa condutividade elétrica, elevada resistência mecânica e principalmente uma alta biocompatibiliadade $^{(1)}$.

\section{Materiais e Métodos}

O material utilizado como substrato para deposição são amostras retangulares de vidro com larguras e comprimentos entre 0,5 e $0,7 \mathrm{~cm}$ e 0,7 a $1,2 \mathrm{~cm}$, respectivamente. A câmara de nitretação a plasma convencional marca SDS, modelo Thor NP 5000 pertencente ao Laboratório de Engenharia de Superfícies do IFES foi adaptada para configuração de deposição por plasma de gaiola catódica, as quais foram confeccionadas em aço inoxidável AISI 304L e em titânio, conforme Fig. 1.
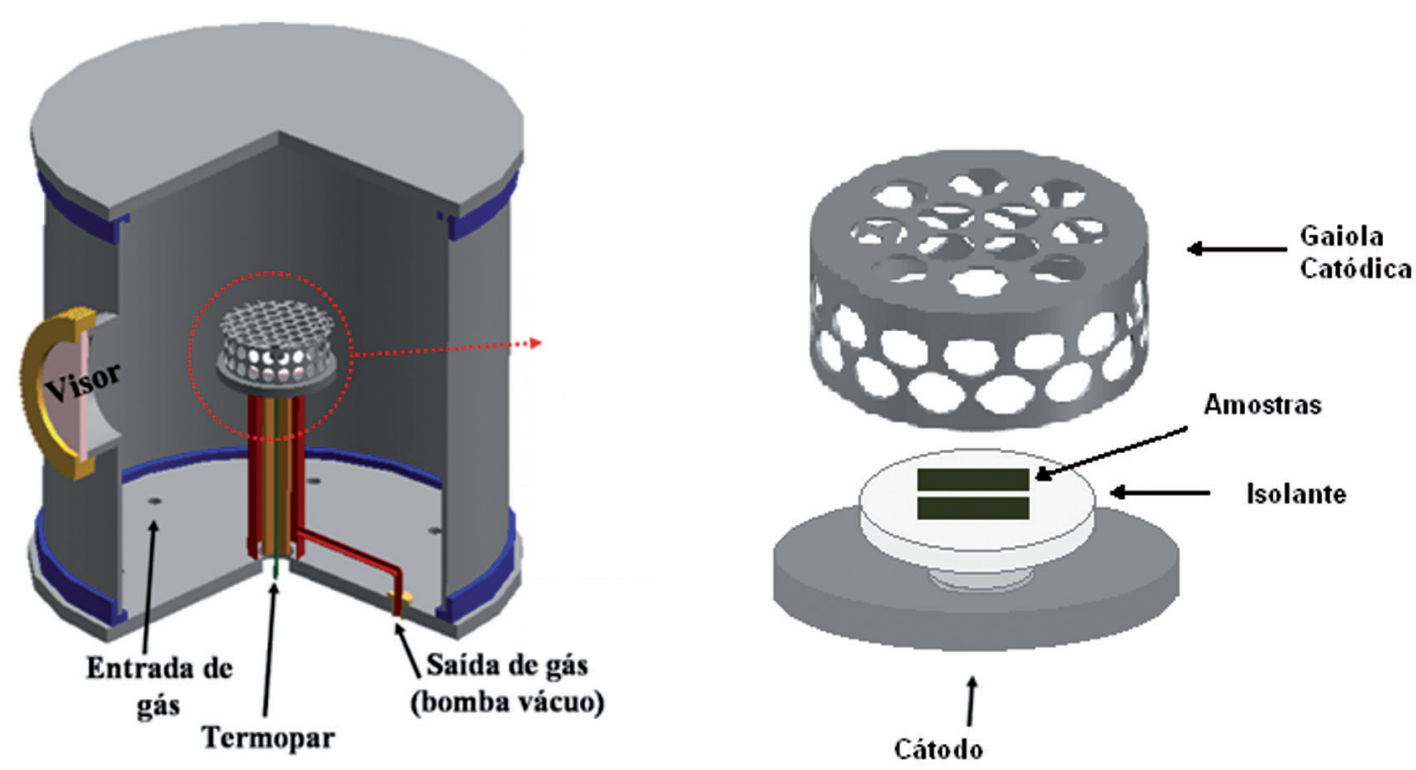

Figura 1. Representação esquemática em corte do reator de nitretação a plasma, mostrando em detalhe a gaiola catódica ${ }^{(1)}$. 
A câmara de nitretação, utilizada para a deposição por plasma com gaiola catódica tem configuração cilíndrica de aço inoxidável AISI 304L com $70 \mathrm{~cm}$ de altura e 50 $\mathrm{cm}$ de diâmetro. O porta amostra do reator é composto de um disco de $22 \mathrm{~cm}$ de diâmetro por $5 \mathrm{~mm}$ de espessura, e age como catodo, já as paredes da câmara atuam como anodo. O reator ainda tem uma fonte de alta tensão elétrica com freqüência de $4 \mathrm{kHz}$, um medidor de pressão e um termopar para controlar a temperatura do processo. As gaiolas utilizadas foram confeccionadas em aço inoxidável austenítico AISI 304L com furos de $8 \mathrm{~mm}$ de diâmetro, sendo que a gaiola tem $9,5 \mathrm{~cm}$ de diâmetro e a gaiola de titânio possui $11 \mathrm{~cm}$ de diâmetro e furos com $8 \mathrm{~mm}$ de diâmetro e em ambos os casos, os espaçamentos são iguais.

As deposições com as gaiolas de aço inoxidável AISI 304L foram realizadas em atmosfera de plasma com $20 \%$ vol. de $\mathrm{N}_{2}$ e $80 \%$ vol. de $\mathrm{H}_{2}$ e as temperaturas foram $435^{\circ} \mathrm{C}, 470^{\circ} \mathrm{C}$ e $505^{\circ} \mathrm{C}$ para tempos correspondentes a $5 \mathrm{~h}, 30 \mathrm{~min}$ e $1 \mathrm{~h}$. Já a deposição em gaiola de titânio a temperatura usada foi $413^{\circ} \mathrm{C}$ e o tempo de tratamento foi $1 \mathrm{~h}$ e $44 \mathrm{~min}$. em atmosfera de plasma com $80 \%$ vol. de $\mathrm{N}_{2}$ e $20 \%$ vol. de $\mathrm{H}_{2}$, sendo a pressão mantida constante em todos os ensaios a 2,5torr. Os experimentos eletroquímicos foram realizados em um potenciostato/galvanostato Ivium Portable CompactStat ${ }^{\mathrm{TM}}$ pertencente ao Laboratório de Corrosão do Programa de Pós Graduação em Engenharia Metalúrgica e de Materiais/IFES tendo como eletrodos de trabalho os filmes de $\mathrm{Fe}_{x} \mathrm{~N}$ e $\mathrm{Ti}_{\mathrm{x}} \mathrm{N}$ depositados sobre substratos de vidro, ambos normatizados pelas respectivas áreas. Os outros eletrodos foram o auxiliar de platina e o de referência de calomelano, enquanto o eletrólito foi uma solução de íons cloreto a 3,5\% em peso. A freqüência utilizada na espectroscopia de impedância eletroquímica foi entre $40 \mathrm{KHz}$ e $4 \mathrm{mHz}$. Os ensaios de difração de raios X foram realizadas em um difratômetro Bruker, modelo D2 PHASER e angulação $2 \theta: 10^{\circ}$ a $100^{\circ}$ e com o uso de radiação de cobre, cujo comprimento de onda é $1,542 \AA$.

\section{Resultados e Discussões}

Os testes termoquímicos foram feitos com o intuito de avaliar a resistência à corrosão dos filmes formados. Para a realização dos diagramas de impedância foi utilizado o software Zview, versão 3.1, enquanto que para as curvas de polarização utilizou-se o Origin, versão 6.0. A Fig. 2(a) apresenta o diagrama de Nyquist, também conhecida como representação de Argand ou Cole-Cole ${ }^{(6)}$ dos filmes de FexN e TixN, tendo como abscissa a componente real da impedância (Z') e como ordenada a componente imaginária da impedância $\left(Z\right.$ ') ${ }^{(7)}$, enquanto a Fig. 2(b) representa o diagrama de Bode, onde o módulo da impedância $(|Z|)$ e o ângulo de fase $(\theta)$ são examinados em função da freqüência ${ }^{(7)}$.

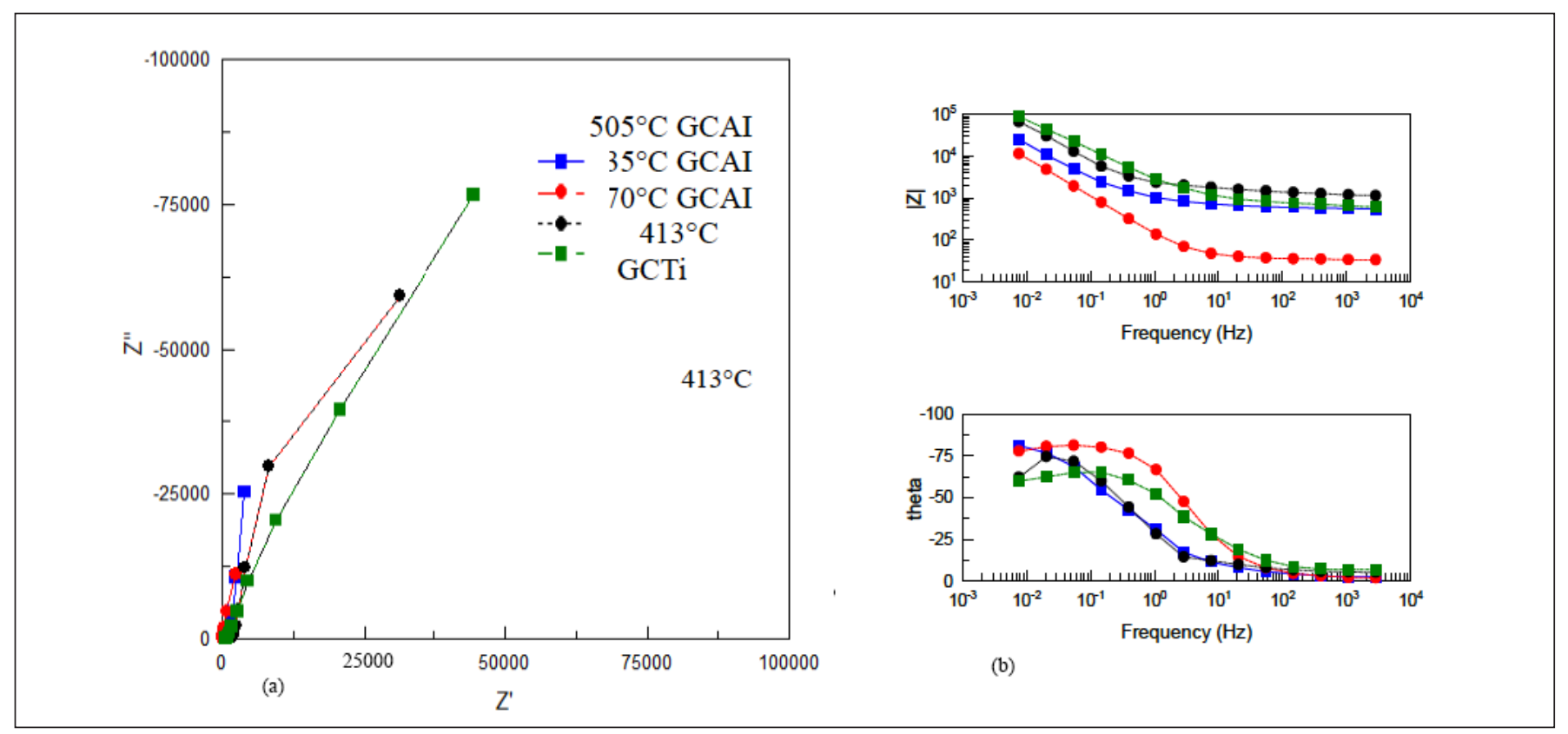

Figura 2. Diagramas de (a) Nyquist e (b) Bode dos filmes de $\mathrm{Fe}_{\mathrm{x}} \mathrm{N}$ e $\mathrm{Ti}_{\mathrm{x}} \mathrm{N}$. 
onde GCAI e CGTi mostrados na legenda da Fig. 2(a) representam: gaiola catódica de aço inoxidável e gaiola catódica de titânio, respectivamente.

Os diagramas de Nyquist são mais utilizados para representar os fenômenos eletroquímicos, enquanto os diagramas de Bode são mais utilizados para representar a impedância eletro-hidrodinâmica. Pela análise da Fig. 2(a) é possível observar que dentre os filmes formados, o filme de TixN $\left(413^{\circ} \mathrm{C}\right.$ CGTi) obteve uma maior resistência à corrosão do que os filmes de $\mathrm{Fe}_{\mathrm{x}} \mathrm{N}$, obtendo maior módulo de impedância pela Fig. 2(b) inferior. A Fig. 3 mostra em detalhe o Diagrama de Nyquist para o filme de $\mathrm{Ti}_{\mathrm{x}} \mathrm{N}$, onde o ponto máximo corresponde à freqüência de $0,007 \mathrm{~Hz}$.

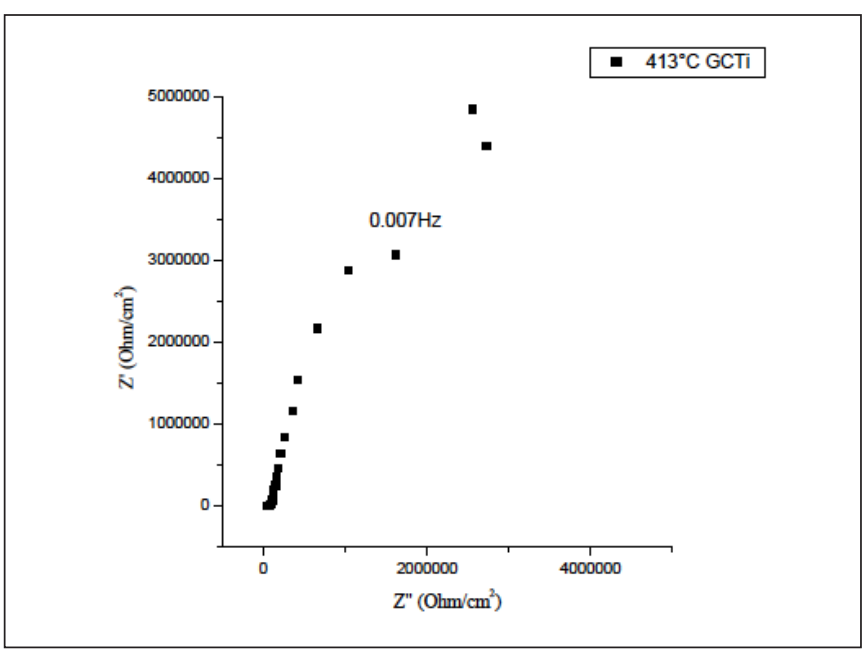

Figura 3. Diagramas de Nyquist do filme de $\mathrm{Ti}_{x} \mathrm{~N}$.

Além da interpretação gráfica, alguns autores propõem o uso de circuitos elétricos equivalentes com o intuito de modelar os resultados de impedância. Entretanto, torna-se um dilema decidir o circuito específico dentro de um número infinito de possibilidades, uma vez que um circuito equivalente envolvendo três ou mais elementos de circuito pode ser rearranjado de vários modos e ainda produzir a mesma impedância ${ }^{(8)}$. No presente trabalho, serão analisados apenas os resultados eletroquímicos da impedância, ou seja, a análise dos diagramas de Nyquist e Bode, sem o uso de circuitos elétricos equivalentes.

Na Fig. 4 foram analisadas as curvas de polarização das amostras em solução de cloreto de sódio $(\mathrm{NaCl})$ a $3,5 \%$ em peso.

Pela análise da Fig. 4 é possível observar que as curvas de polarização possuem comportamentos semelhantes,

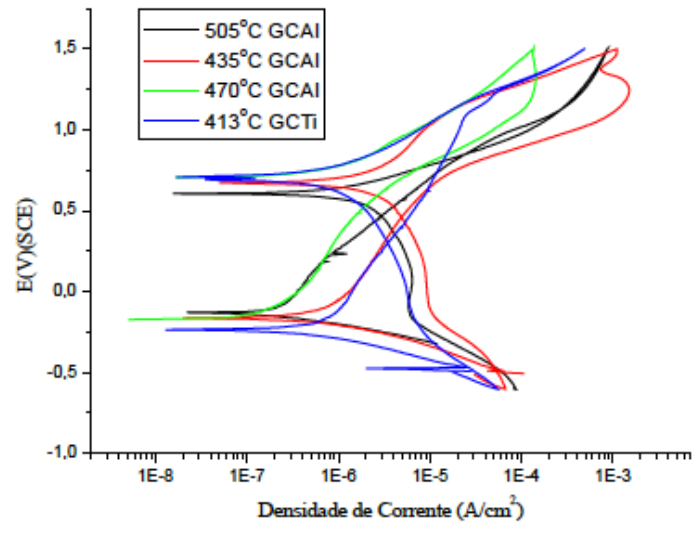

Figura 4. Curvas de polarização dos filmes de $\mathrm{Fe}_{x} \mathrm{~N}$ e $\mathrm{Ti}_{x} \mathrm{~N}$.

ocorrendo transpassivação em todas as amostras, ou seja, ao atingir um potencial muito elevado, pode-se iniciar a ruptura e a degradação do filme passivado, dissolvendo-o na solução e esse comportamento é observado quando a curva de polarização sofre um aumento abrupto da corrente, caracterizando assim, o fenômeno de transpassivação ${ }^{(9)}$. Na amostra $413^{\circ} \mathrm{C} \mathrm{CGTi} \mathrm{observou-se} \mathrm{o} \mathrm{menor}$ valor de densidade de corrente, $1 \times 10^{-8} \mathrm{~A} / \mathrm{cm}^{2}$, ou seja, houve uma menor transferência de elétrons, o que leva a uma menor taxa de corrosão, dentre os filmes estudados.

A difração por Raios-X (DRX) possui caráter qualitativo, uma vez que identifica as estruturas das fases cristalinas presentes na amostra. A Fig. 5 mostra os difratogramas dos filmes de $\mathrm{Fe}_{\mathrm{x}} \mathrm{N}$.

Com base na Fig. 5 é possível observar a presença de picos principalmente na amostra com $5 \mathrm{~h}$ de tratamento. Já sabermos que existem fatores que influenciam a cristalinidade dos filmes que é manifestada pela presença dos planos cristalinos. Dentre esses fatores, podemos citar: o tipo e temperatura do substrato, tempo de tratamento, além de fatores ligados a gaiola.

Nos difratogramas em detalhe podemos observar os diferentes picos, por exemplo, em dois theta iguais a 41,3 e 47.8 correspondem aos planos cristalográficos (110) e (111) da fase $\mathrm{S}$, austenita expandida, que segundo alguns autores ${ }^{(10)}$ é formado pelos nitretos do tipo FexN. Esses resultados indicam que o filme depositado é característico de estrutura cristalina de face centrada (CFC), sendo o plano (111) o mais denso e o mais intenso dessas estruturas cristalinas.

A Fig. 6 apresenta o difratograma do filme de $\mathrm{Ti}_{\mathrm{x}} \mathrm{N}$ com destaque para o plano cristalográfico (200) com maior intensidade na posição correspondente ao plano (200) e um pico menor na posição $2 \theta$ igual a 50,8 que corresponde ao plano (211). O picos em $2 \theta$ iguais a 90,7 e $95,8^{\circ} \mathrm{C}$ correspondem 


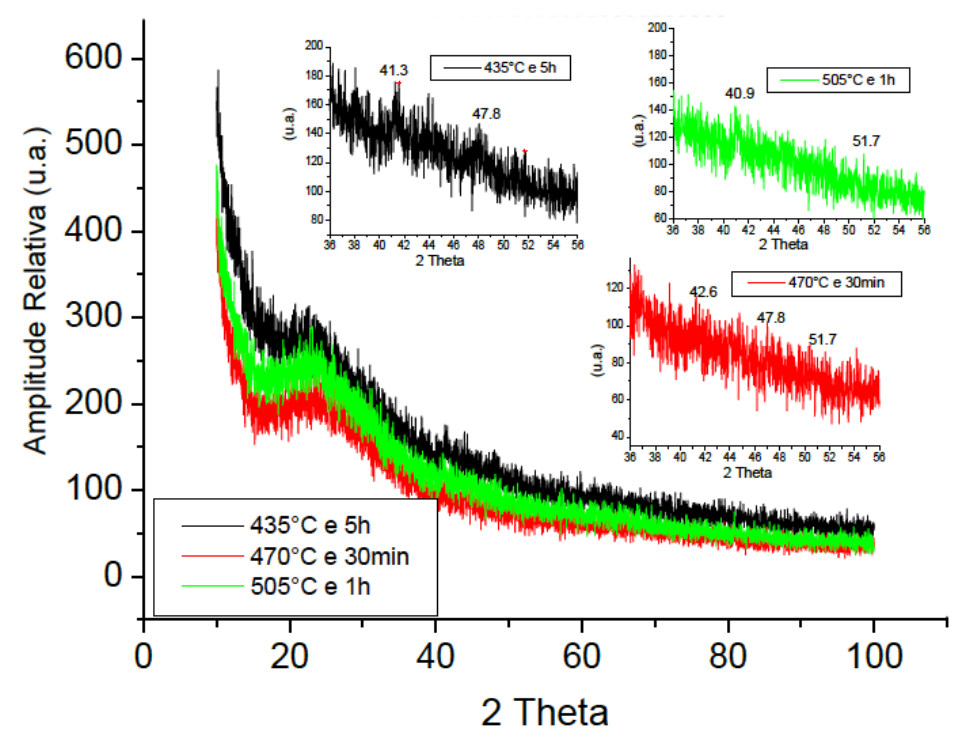

Figura 5. Difratogramas dos filmes de $\mathrm{Fe}_{\mathrm{x}} \mathrm{N}$.

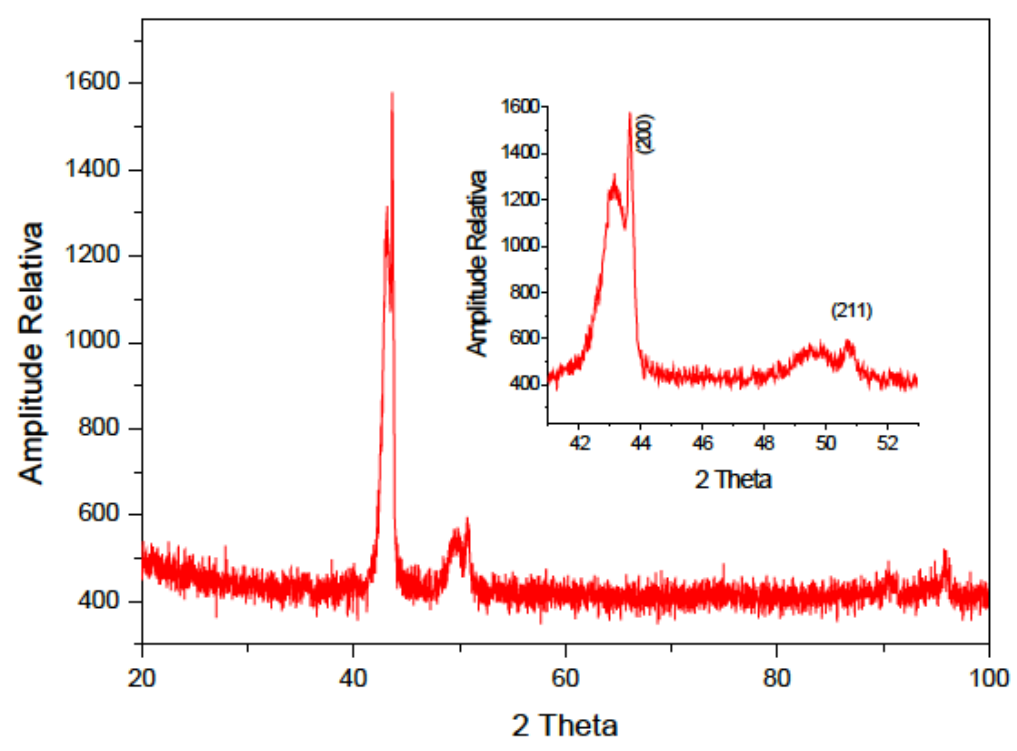

Figura 6. Difratogramas do filme de $\mathrm{Ti}_{x} \mathrm{~N}$.

aos planos cristalográficos (035) e (217), respectivamente. A análise de difratometria de raios-x revela que nessa amostra pode ter tido a formação da fase $\delta$-TiN com texturas (200) e uma mistura da fase $\delta$-TiN(111) com a $\varepsilon$-Ti2N(200).

\section{Conclusões}

A deposição por plasma em descarga de gaiola catódica apresentou resultados satisfatórios principalmente para o filme de $\mathrm{Ti}_{\mathrm{x}} \mathrm{N}$ tratado a $413^{\circ} \mathrm{C}$ e $1 \mathrm{~h}$ e $44 \mathrm{~min}$. Em geral, os filmes de $\mathrm{Fe}_{x} \mathrm{~N}$ tratados a $505^{\circ} \mathrm{C}$ e $1 \mathrm{~h}$ e $470^{\circ} \mathrm{C}$ apresentaram melhores resultados do que o filme tratado a $435^{\circ} \mathrm{C}$ e $5 \mathrm{~h}$, provavelmente por este ter um longo período de tratamento. Além disso, os ensaios eletroquímicos apresentaram coerência entre si, uma vez que a interpretação dos diagramas de Nyquist e Bode e das curvas de polarização apontaram uma taxa de corrosão satisfatória. Estes fatos confirmam que a técnica de deposição por plasma em descarga de gaiola catódica é uma boa alternativa para a obtenção 
de filmes finos e, além disso, utiliza uma estrutura simples de tratamento, típica dos reatores de nitretação a plasma.

\section{Agradecimentos}

À CAPES pela concessão da bolsa de mestrado e aos colegas George Simonelli pela ajuda na deposição de filmes finos, Ricardo Salvador pelo ensaio de difração de raio-X, aos mestrandos do PROPEMM/IFES Denner de Mello pelas discussões sobre impedância e Maycoln Depianti Conci pela confecção da gaiola de aço inoxidável 304L e a empresa NCS Industrial, Fabricação e Serviços LTDA ME pela confecção da gaiola de titânio.

\section{Referências}

1. Daudt, N.F.; Barbosa, J.C.P.; Macêdo, M.O.C.; Nascimento Neto, A.B.; Guerra Neto, C.L.B.; Alves Jr, C.; Estudo da viabilidade da técnica de plasma em descarga de gaiola catódica para obtenção de filmes de tin par revestimentos biocompatíveis, Brasil, 2011.

2. Souza, R.R.M; Araújo, F.O; Costa, J.A.P; Brandim, A.S; Brito, R.A; Alves Jr., C.; Cathodic Cage plasma nitriding: An innovative technique, Hindawi Publishing Corporation Journal of Metallurgy, v. 2012, Article ID 385963, 6 pages, 2011.

3. Araújo, F.O; Souza, R.R.M; Costa, J.A.P; Alves Jr, C.; Deposição de filme metálico em amostras de vidro em gaiola catódica, Revista Brasileira de Aplicações de Vácuo, v. 27, n. 3, 149-152, 2008.

4. Alves Jr., C.; Nitretação a plasma: Fundamentos e aplicações, Rio Grande do Norte, Brasil, 2001, p. 90.

5. Souza, R.R.M.; Nitretação em plasma com gaiola catódica: Investigação do mecanismo e estudo comparativo com a nitretação em plasma de tensão contínua. Tese de Doutorado (2007). Universidade Federal do Rio Grande do Norte, Natal (RN).

6. Wolynec, S.; Técnicas eletroquímicas em corrosão, São Paulo, Brasil, 2002, p.115.

7. Silva,A.G.S.G.; Estudo do comportamento eletroquímico do nióbio sob carregamentos e descarregamento de hidrogênio. Dissertação de Mestrado (2007). Universidade Federal do Paraná, Curitiba (PR).

8. Vergés, G. R.; Estudo do desempenho de sistemas de pintura para materiais das redes de distribuição de energia elétrica situadas em regiões litorâneas. Dissertação de Mestrado (2005). Universidade Federal do Paraná, Curitiba (PR).

9. Fattah-Alhosseini, A.; Mosavi, M.; Allahdadi, A.; An Electrochemical Impedance Study of AISI 321 Stainless Stell in $0.5 \mathrm{M} \mathrm{H} 2 \mathrm{SO}$. International Journal of Electrochemistry. Vol. 2011, 10 páginas.

10. Gontijo, L.C.; Machado, R.; Miola, E.J; Casteletti, L.C.; Alcântara, N.G.; Nascente, P.A.P.; Study of the S phase formed on plasma-nitrided AISI 316L stainless steel. Materials Science and Engineering A431 (2006) 315-321. 